\title{
Helicobacter pylori Is Not Eradicated after Triple Therapy: A Nested PCR Based Study
}

\author{
Saurabh Kumar Patel, ${ }^{1}$ Girish Narayan Mishra, ${ }^{2}$ Chandra Bhan Pratap, ${ }^{1}$ \\ Ashok Kumar Jain, ${ }^{3}$ and Gopal Nath ${ }^{1}$ \\ ${ }^{1}$ Department of Microbiology, Institute of Medical Sciences, Banaras Hindu University, Varanasi, Uttar Pradesh 221005, India \\ ${ }^{2}$ Department of Medicine, Institute of Medical Sciences, Banaras Hindu University, Varanasi, Uttar Pradesh 221005, India \\ ${ }^{3}$ Department of Gastroenterology, Institute of Medical Sciences, Banaras Hindu University, Varanasi, Uttar Pradesh 221005, India
}

Correspondence should be addressed to Gopal Nath; gopalnath@gmail.com

Received 27 February 2014; Revised 7 June 2014; Accepted 7 June 2014; Published 23 June 2014

Academic Editor: Kathleen Montone

Copyright (C) 2014 Saurabh Kumar Patel et al. This is an open access article distributed under the Creative Commons Attribution License, which permits unrestricted use, distribution, and reproduction in any medium, provided the original work is properly cited.

\begin{abstract}
Detection of Helicobacter pylori after triple therapy is usually carried out by either rapid urease test (RUT), urea breath test (UBT), histology, bacterial isolation, and single round PCR or serological tests. In this study, antral biopsy specimens from 25 patients were tested for $H$. pylori by RUT, culture, histology, and nested PCR in their antral biopsy specimens before and after treatment. Three genes, namely, heat shock protein ( $h s p 60)$, phosphoglucosamine mutase (ureC), and flagellar export ATP synthase (fliI) of $H$. pylori were targeted. Of the 25 antral biopsy specimens, the RUT, culture, histology, and nested PCR positivity dropped from $81.8 \%$ to $12 \%, 31 \%$ to $0 \%, 100$ to $84 \%$, and $100 \%$ to $92 \%$, respectively, before and after therapy. Further, $h s p 60$ specific amplicons from 23 out of 25 patients gave identical restriction pattern, while 6 fli I and 1 ure $C$ specific amplicon produced different restriction pattern. Furthermore, variations in fli gene sequences in $\mathrm{H}$. pylori after treatment were also confirmed by sequencing and compared in silico. Nested PCR based detection of $H$. pylori is more sensitive method to detect $H$. pylori after therapy than culture, RUT, and histology. Further, this study suggests that H. pylori is not eradicated completely after triple therapy.
\end{abstract}

\section{Introduction}

Association of Helicobacter pylori (H. pylori) with acid peptic diseases including duodenal ulcer is well established [1]. Further, $H$. pylori has been designated as class I carcinogen by WHO [2]. Although, prevalence of $H$. pylori ranges between 20 and $80 \%$ in different geographical areas depending on different socioeconomic factors, eradication has been advised only in symptomatic cases [3-6]. Triple therapy constituting omeprazole, amoxicillin, and clarithromycin has been found to be quite effective to eliminate $H$. pylori from stomach $[7,8]$. However, occasional recurrences have been reported with isolation of strain similar to that of pretreatment [9-13]. It is not clear whether the infection persisted after triple therapy or reinfection occurred from the other niches, for example, oral cavity, or acquired from other close family members. For primary diagnosis and posttherapy evaluation of $H$. pylori, most of the studies have used rapid urease test (RUT)/CLO test, histology, $\mathrm{C}^{13 / 14}$-urea breath test (UBT), and culture and stool antigen detection test. Because of poor sensitivity of isolation of $\mathrm{H}$. pylori, histology and UBT are usually considered as gold standard for the assessment of eradication therapy. But these tests are found sensitive enough only when density of $H$. pylori remains high. Contrary to this, PCR based technique can detect even a few bacteria. There are scant reports using single round PCR based detection of $H$. pylori after therapy. It has already been established that the sensitivity of nested PCR based detection is very high in comparison to single round [14]. Interestingly, there is no report till date by using nested PCR based detection of the bacterium after eradication therapy in $H$. pylori associated diseases. Therefore, present study was planned to see whether, $H$. pylori is really eradicated by using nested PCR protocol and if not, whether the persistent strains are the same or different. 


\section{Methods}

2.1. Patient Selection. This study was conducted at Sir Sunder Lal Hospital, Banaras Hindu University, Varanasi, during June, 2009 to March, 2010. Ethical committee clearance was obtained before commencement of the study and well informed written consent was obtained from each of the participants. The patients who had severe acid peptic diseases on endoscopy with positive test for $H$. pylori were given clarithromycin $500 \mathrm{mg}$, amoxicillin $1 \mathrm{gm}$, and pantoprazole $40 \mathrm{mg}$; all twice daily for 14 days. Patients were initially asked to visit again for follow up at 4 weeks after the completion of anti- $H$. pylori therapy. A total of 93 patients (63 male and 30 female; mean age $42.4 \mathrm{y}$; age range 20 to $85 \mathrm{y}$ ) were enrolled in the present study. Biopsies were collected in the endoscopy units of the Department of Gastroenterology. Patients taking proton pump inhibitors and/or antibiotics having bleeding ulcers or an acute hemorrhage from other sites in the upper gastrointestinal tract and patients with stomach surgery were excluded. The endoscope was mechanically washed and then disinfected using activated $2 \%$ glutaraldehyde. The $4-5$ biopsy specimens were collected from each patient of the 93 enrolled patients. A total of 25 patients who had antral gastritis $(n=12)$ and peptic ulcer $(n=13)$ diagnosed previously could be followed up and upper gastrointestinal endoscopy was performed on both the occasions, that is, pre- and posttherapy, and biopsy samples were collected from gastric antrum. Since 68 patients did not report for the follow up after treatment, they were excluded and only 25 patient's antral biopsies could be analyzed in this study.

2.2. Rapid Urease Test (RUT). For RUT, biopsy was inoculated into $1 \mathrm{~mL}$ of $10 \%$ urea dissolved in deionized water $(\mathrm{pH}$ 6.8 ), to which two drops of $1 \%$ phenol red solution were added and incubated at $37^{\circ} \mathrm{C}$ for $24 \mathrm{~h}$. A positive result was recorded when the color changed from yellow to pink within $30 \mathrm{~min}$ [15].

2.3. Histology. Antral biopsy specimens, collected during pre- and posttreatment were fixed in $10 \%$ buffered formalin, embedded in paraffin. Paraffin sections were stained with hematoxylin and eosin to examine the presence/absence of curved rod shaped $H$. pylori on the mucosal surface.

2.4. Culture of H. pylori from Gastric Biopsy Specimens. The biopsy piece was homogenized into phosphate buffer saline (PBS) in an all glass disposable homogenizer. This tissue homogenate was plated onto the media containing brain heart infusion (BHI) agar (Difco, Becton Dickinson, Sparks, MD, USA), supplemented with $7 \%$ sheep blood, $0.4 \%$ IsoVitaleX, and Skirrow selective supplement (vancomycin $10 \mu \mathrm{g} / \mathrm{mL}$; polymixin B sulfate $2.5 \mathrm{IU} / \mathrm{mL}$; trimethoprim lactate $5 \mu \mathrm{g} / \mathrm{mL}$ ) (Difco, Becton Dickinson, Sparks, MD, USA). Plates were incubated at $37^{\circ} \mathrm{C}$ in an atmosphere of $5 \% \mathrm{O}_{2}, 10 \%$ $\mathrm{CO}_{2}$, and $85 \% \mathrm{~N}_{2}$ for 3-7 days. Plates were opened after $72 \mathrm{~h}$ and every $24 \mathrm{~h}$ afterwards, if no growth was obtained. Plates were discarded only after 7 days of incubation. Organisms were identified as $H$. pylori based on typical colony morphology, Gram staining, and positive oxidase, catalase, and rapid urease tests [15].

2.5. Preparation of Genomic DNA for PCR Assay. Genomic DNA from tissue homogenate was extracted using a standard proteinase K and phenol-chloroform method [16]. One set of double distilled water was included in each batch of DNA extraction to check cross-contamination of DNA during DNA extraction.

2.6. PCR Amplification. PCR was carried out in a $25 \mu \mathrm{L}$ volume using $10 \mathrm{ng}$ of DNA, $1 \mathrm{U}$ of Taq polymerase (Bangalore Genie, India), and $10 \mathrm{pmol}$ of each primer (SBS Genetech), $0.25 \mathrm{mM}$ (each) deoxynucleotide triphosphate, and $1.5 \mathrm{mM}$ $\mathrm{MgCl}_{2}$ in standard PCR buffer. For the internal amplification, the PCR product from the primary cycle was diluted 1/50 and $1 \mu \mathrm{L}$ was used as the template in the nested PCR [15]. All the amplifications were carried out in a thermal cycler (Biometra, Goettingen, Germany). Details of primers and their protocol are given in Table 1. Amplification of all the three conserved genes were carried out by nested protocol. Universal eubacterial primers were used for all the samples to exclude PCR inhibition. DNA from $H$. pylori reference BHUHPSKP3 (KC525436) and a tube containing water in place of DNA were assayed in each PCR run as positive and negative controls, respectively. The PCR products were analyzed by electrophoresis on $1.4 \%$ agarose gels (Bangalore Genie, India) containing $0.5 \mu \mathrm{g}$ of ethidium bromide per $\mathrm{mL}$. The gel was run at $70 \mathrm{~V}$ with TBE (Tris Boric acid EDTA) buffer and was examined by transilluminator and photographed.

2.7. PCR Based Restriction Enzyme Analysis (PCR-REA). After amplification, the PCR products [hsp60, ureC or $\mathrm{glm} M$, and fli gene] were precipitated with 2.5 volumes of ethanol. The pellets were washed twice with $75 \%$ ethanol and dissolved in Tris-EDTA buffer ( $\mathrm{pH} 8.0$ ). A $10 \mu \mathrm{L}$ precipitated amplified DNA was then digested with the $10 \mathrm{U}$ of restriction enzyme in appropriate buffered solution recommended by the manufacturer (Genie, Bangalore, India) and incubated for $3 \mathrm{~h}$ at $37^{\circ} \mathrm{C}$. Hind III restriction enzyme was used for $h s p 60$ and $u r e C$, and $M n l$ I was used for fli gene. The digested DNA fragments were analyzed by electrophoresis on $2 \%$ agarose gels (Genie, Bangalore, India) containing $0.5 \mu \mathrm{g}$ of ethidium bromide per $\mathrm{mL}$. The gel was run at $70 \mathrm{~V}$ with TBE (Tris Boric acid EDTA) buffer for $3 \mathrm{~h}$ and was examined by transilluminator and photographed. The sizes of digested DNA fragments were estimated from migration distances of a 100-bp DNA ladder molecular weight standard (Genie, Bangalore, India) and compared with in silico restriction digestion specified with concerned restriction enzyme.

2.8. Sequencing. The amplified fli gene segment, which had different restriction pattern from previous strain were purified from salts and primers using HiPura silica kit for DNA isolation (HiMedia). A total of 6 (5 mutated and 1 wild type) purified amplicons generated 


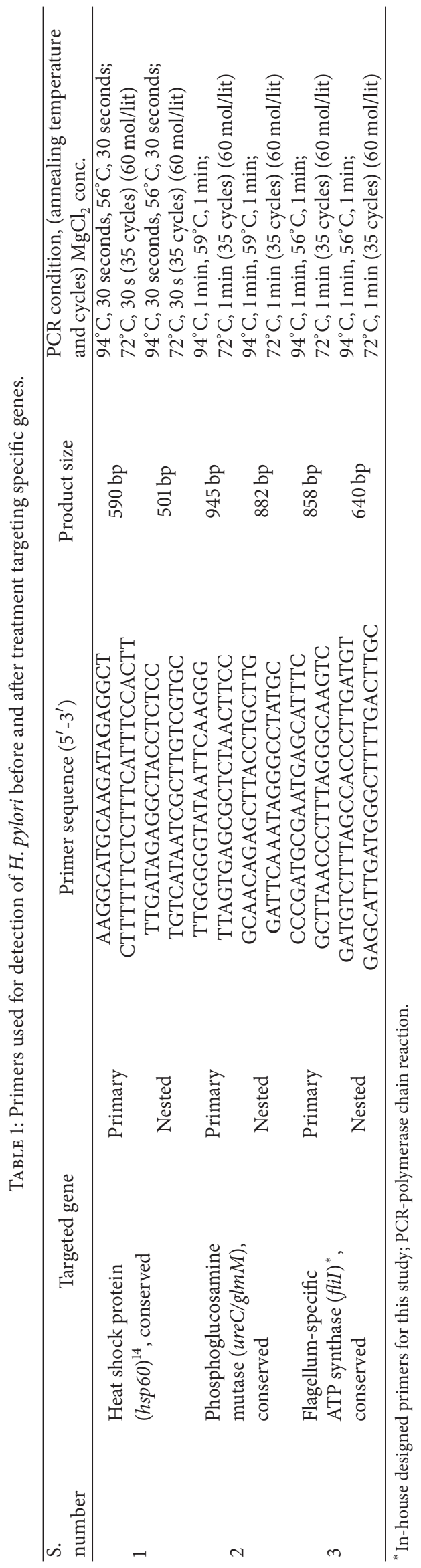


TABLE 2: Representation of strains of $H$. pylori after nested PCR restriction analysis.

\begin{tabular}{|c|c|c|c|c|c|c|}
\hline \multirow{3}{*}{ Biopsy specimens } & \multicolumn{6}{|c|}{ Restriction pattern of partial amplified genes of $H$. pylori by different restriction enzymes } \\
\hline & \multicolumn{2}{|c|}{ hsp 60 by Hind III } & \multicolumn{2}{|c|}{ ureC $(g \operatorname{lm} M)$ by Hind III } & \multicolumn{2}{|c|}{ fliI by $M n l \mathrm{I}$} \\
\hline & Before therapy & After therapy & Before therapy & After therapy & Before therapy & After therapy \\
\hline NUDG11 & A & A & A & A & A & A \\
\hline NUDG13 & A & A & A & A & A & A \\
\hline PUDG18 & A & A & A & A & A & AA \\
\hline NUDG35 & A & A & A & A & A & A \\
\hline NUDG37 & A & A & A & A & A & A \\
\hline PUDG43 & A & A & A & A & A & A \\
\hline NUDG46 & A & A & A & A & A & $\mathrm{AB} 1$ \\
\hline PUDG47 & A & - & A & - & A & - \\
\hline PUDG57 & A & A & A & A & A & A \\
\hline NUDG61 & A & A & A & A & A & A \\
\hline PUDG63 & A & A & A & A & A & A \\
\hline NUDG64 & A & A & A & A & A & A \\
\hline NUDG67 & A & A & A & $\mathrm{AX}$ & A & $\mathrm{A}$ \\
\hline PUDG73 & A & A & A & $\mathrm{A}$ & A & $\mathrm{AB} 2$ \\
\hline NUDG80 & A & A & A & A & A & AA \\
\hline PUDG81 & A & A & A & A & A & A \\
\hline PUDG85 & A & - & A & - & A & - \\
\hline PUDG88 & A & A & A & A & A & $\mathrm{AC}$ \\
\hline NUDG95 & A & A & A & A & A & $\mathrm{A}$ \\
\hline NUDG96 & A & A & A & A & A & A \\
\hline PUDG101 & A & A & A & A & A & A \\
\hline PUDG104 & A & A & A & A & A & $\mathrm{A}$ \\
\hline NUDG109 & A & A & A & A & A & $\mathrm{AA}$ \\
\hline PUDG115 & A & A & A & A & A & $\mathrm{A}$ \\
\hline PUDG118 & A & A & A & A & A & A \\
\hline
\end{tabular}

Fragment length of AX-303 and 579 bp; AA-486 and 154 bp; AB1-386, 154, 55, and 45 bp; AB2-386, 134, 55, 45, and 22 bp; and AC-431, 300, and 154 bp.

targeting fliI were outsourced for partial sequencing to Genei, Bangalore, India. Sequences were analyzed using BLASTN (http://www.ncbi.nlm.nih.gov/BLAST/) to verify mutations/changes in the sequences of fliI gene specific for H. pylori.

\section{Results}

3.1. Bacteriological Study. Of the 25 antral biopsy specimens collected from patients, $81.8 \%(18 / 25)$ were found positive by RUT and $31 \%(7 / 25)$ by culture for $H$. pylori, before triple therapy. Four weeks after anti-H. pylori triple therapy, 3 (12\%) patients (2 PUD and 1 gastritis) were positive by RUT and none of them were positive for $H$. pylori isolation after triple therapy.

3.2. Histology. Of the 25 patients with gastroduodenal diseases that completed eradication treatment, $16 \%$ (4/25) were still $H$. pylori positive by histology.

3.3. Nested PCR. Genomic DNA extracted from biopsy specimens were subjected to amplification by primers specific for $h s p 60$, ureC, and fli genes of $H$. pylori. All the 25 patients were positive for the $501 \mathrm{bp}, 840 \mathrm{bp}$, and $640 \mathrm{bp}$ of amplicon for $h s p 60$, ureC, and fliI genes, respectively, before therapy. However, 92\% (23/25) antral biopsies were positive for $H$. pylori gDNA by nested PCR after 4 weeks, while 2 patients were found negative (Figures 1, 2, and 3).

3.4. PCR-REA. The amplified PCR products of hsp60 gene were digested by Hind III enzyme. All nested amplicons of 501 bp were restricted into two fragments of 310 and 191 bp by the Hind III restriction enzyme. There was no difference in restriction pattern of amplified partial $h s p 60$ gene of strains of H. pylori before and after treatment (Table 2; Figure 4).

The amplified PCR products of ure $C$ gene were restricted by Hind III enzyme. All amplified PCR products were restricted into 3 segments of 435, 303, and $144 \mathrm{bp}$. Strains amplified from all the patients were same except one patient with antral gastritis. The amplicon from this tissue restricted only into fragments of 303 and 579 bp (Table 2; Figure 5).

The amplified PCR products of fliI gene were digested using $M n l$ I enzyme. Digestions of PCR product with $M n l$ I resulted into 3 fragments of 431, 154, and 55 bp similar to in silico. The DNA amplified from the 17 patients were identical, while 6 patients exhibited different restricted pattern than 


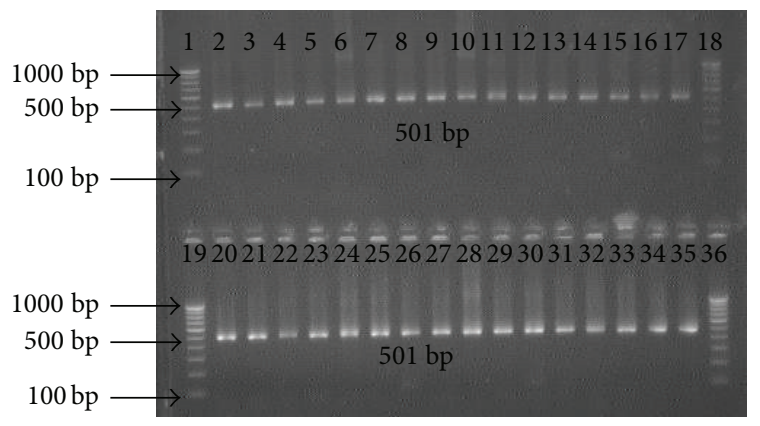

FIgURE 1: Amplification of partial $501 \mathrm{bp} h s p 60$ gene with specific nested primer for $H$. pylori in antral biopsies. Lanes 1, 18, 19, and 36: molecular marker (100 bp); lanes 2 and 20: positive control; lanes 3 to 17: gDNA from antral biopsies before treatment; and lanes 21 to 35: gDNA from antral biopsies after treatment.

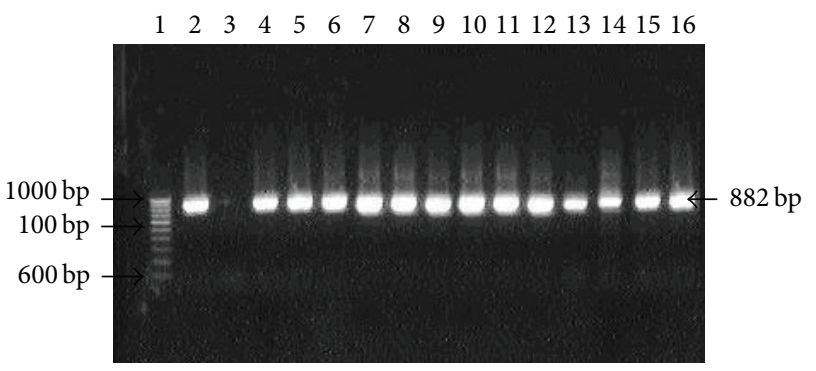

FIgUre 2: Amplification of ureC $(\mathrm{g} \operatorname{lm} M)$ gene with internal nested primer specific for $H$. pylori in antral biopsies. Lane 1: molecular marker (100 bp); lane 2: positive control; lane 3: negative control; lanes 4 to 16: gDNA from antral biopsies collected after treatment.

what were obtained before therapy ( 4 with peptic ulcer and 2 had antral gastritis). Restriction pattern of amplified fli gene of $H$. pylori from 6 patients exhibited four different types. Three patients were type $\mathrm{A}$, while remaining 3 strains belonged to each of the B1, B2 and C types. Type A strain showed two fragments of 486 and $154 \mathrm{bp}$. Type B was fragmented into three fragments 386,154 , and $55 \mathrm{bp}$, but on the ground of sequencing type $\mathrm{B}$ was further subdivided into two subgroups B1 and B2. Subtype B1 was restricted into $386,154,55$, and $45 \mathrm{bp}$ and subtype B2 was digested into $386,134,55,45$, and $22 \mathrm{bp}$. However, the smaller fragments could not be visualized on $1.8 \%$ agarose gel. Type $\mathrm{C}$ amplicon could be digested into 3 fragments, that is, 431, 300, and 154 bp (Table 2; Figure 6). However, this type could not be sequenced.

3.5. DNA Sequence of fliI Gene before and after Treatment and In Silico Restriction. DNA sequences of fli gene have been submitted to NCBI gene data Bank (GenBank accession number KC525439, KC525440, KC525441, KC525442, and KC525443). Comparison of the nucleotide sequences with the NCBI database showed $99 \%$ similarity with $H$. pylori flagellum-specific ATP synthase (fliI). The partial nucleotide sequence of $f l i$ of 5 strains were flanked with nucleotide

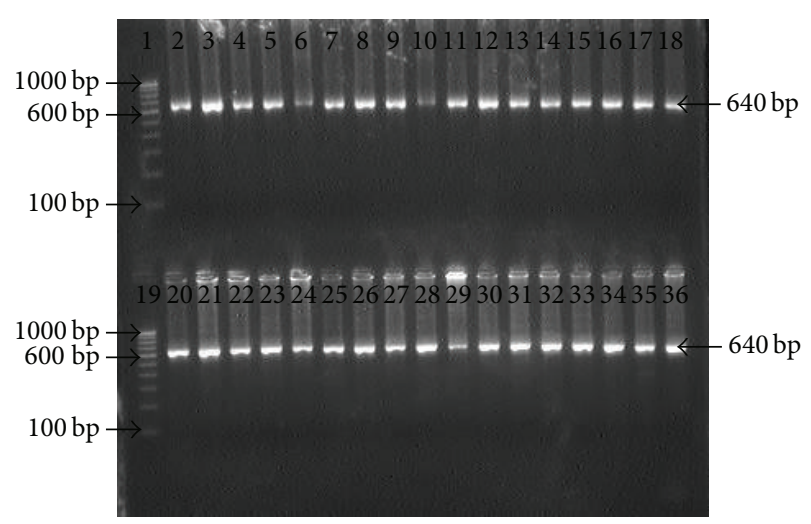

FIGURE 3: Electrophotograph showing amplification of fliI gene with specific internal primer for $H$. pylori in antral biopsies. Lanes 1 and 19: molecular marker (100 bp); lanes 2 and 20: positive control; Lanes 3 to 18: gDNA from antral biopsies before treatment; and Lanes 21 to 35: gDNA from antral biopsies after treatment.

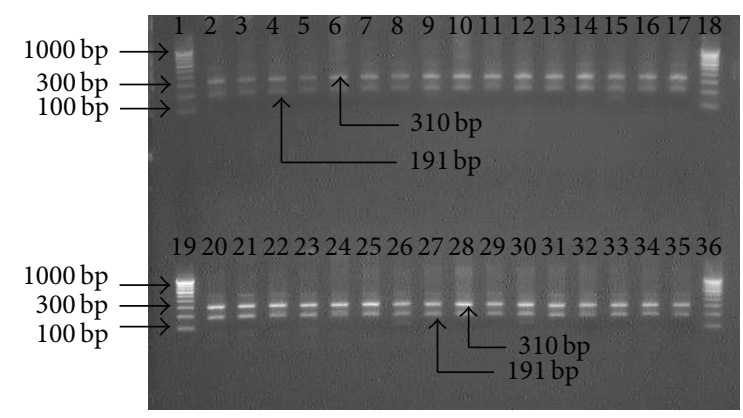

FIGURE 4: Electrophotograph of restriction digestion of $h s p 60$ gene of H. pylori strains with Hind III, restricted $501 \mathrm{bp} h s p 60$ gene amplicon into two fragments (310 and $191 \mathrm{bp}$ ). Lanes 1, 18, 19, and 36: 100 bp molecular marker; lanes 2 to 17: restriction pattern of PCR product specific to $h s p 60$ before treatment; lanes 20-35: restriction pattern of amplicons specific to $h s p 60$ gene after treatment.

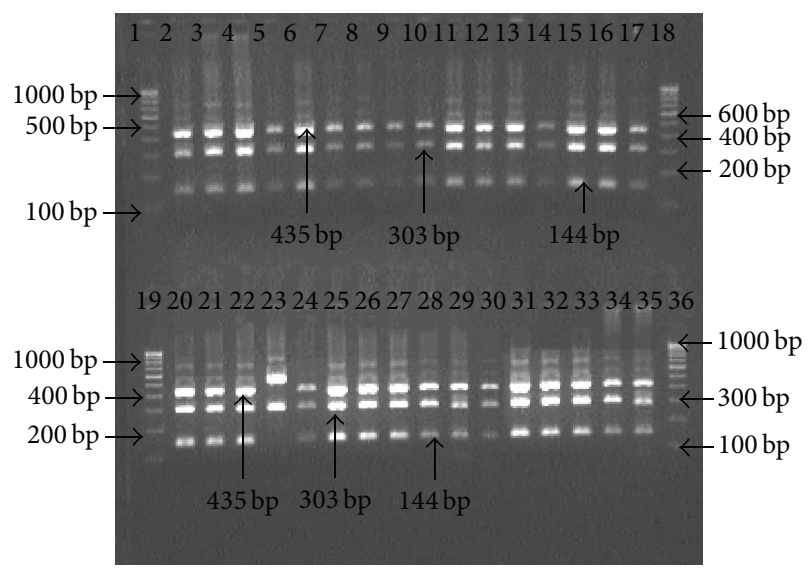

FIGURE 5: Electrophotograph of restriction analysis of ureC $(\mathrm{glmM})$ gene of $H$. pylori strains with Hind III, restricted 882 bp ureC gene amplicon into 3 fragments $(435,303$, and $144 \mathrm{bp})$. Lanes 1, 18, 19, and 36: $100 \mathrm{bp}$ molecular marker; lanes 2 to 17: restriction pattern of PCR product specific to ure C before treatment; lanes 20-35: restriction pattern of amplicons specific to ure $C$ gene after treatment. 


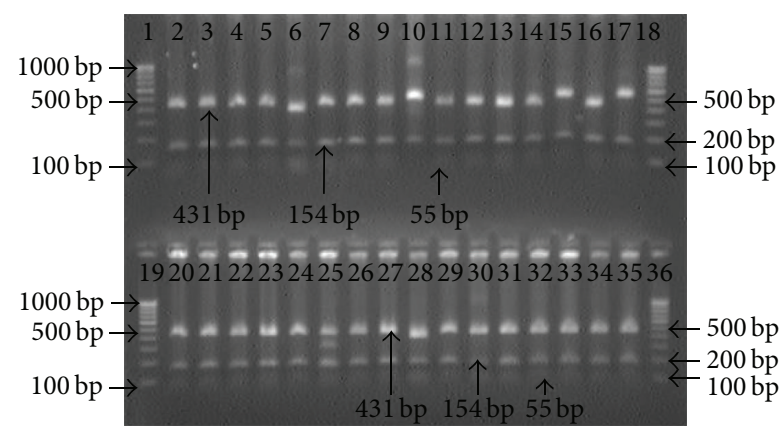

FIGURE 6: Electrophotograph of restriction digestion of fli gene of H. pylori strains with $\mathrm{Mnl} \mathrm{I}$, restricted $640 \mathrm{bp}$ fliI gene amplicon into three fragments $(431,154$, and $55 \mathrm{bp})$. Lanes $1,18,19$, and 36 : 100 bp molecular marker; lanes 2 to 17: restriction pattern of PCR product specific to $\mathrm{fli}$ after treatment; lanes $6,10,15$, and 17 exhibited different band pattern comparison to their previous strains; and lanes 20-35: restriction pattern of amplicons specific to fli gene before treatment.

sequences from $J 99$ as reference up to $640 \mathrm{bp}$ similar to internal amplicon with assurance that no additional site could be generated during flanking. All the five sequenced nucleotides were restricted by $\mathrm{Mnl} \mathrm{I}$ in silico (Figure 7). In silico restriction pattern was similar to experimental observation.

\section{Discussion}

The positivity for $H$. pylori in 23 of 25 patients (92\%) who came for follow up after 4 weeks of completion of anti- $H$. pylori therapy is really surprising in the light of previous reports, where eradication rates ranged between 70 and $100 \%$. This remarkable difference may be explained on the basis of relatively poor sensitivity of $H$. pylori detection by serological, UBT, fecal antigen, RUT, histopathology, culture, and single round PCR methods than by nested PCR. Anti-H. pylori antibody based method could demonstrate eradication rate of $85 \%$, but it should be taken in the light of the fact that antibody fall may take time and also presence of $H$. pylori in body sites other than stomach cannot be excluded. UBT has been found to show eradication rates ranging between 75 and $100 \%$. However, for positivity by UBT, urease producing bacterial density in stomach should be sufficient enough which is naturally reduced significantly by anti- $H$. pylori regimen. The same logic of low $H$. pylori density in stomach very well explains the quite high eradication rate assessed by fecal antigen detection, RUT, histology, single round PCR, and bacterial isolation methods. Further RUT, UBT and bacterial isolation primarily depends on viable and metabolically active form of $H$. pylori. But this is already established that the antimicrobial therapy not only causes reduction in bacterial load but also transforms active spiral bacteria to coccoid (viable but not culturable: VBNC) form [17, 18]. Further, single round PCR may give positive amplification only when more than 70 bacterial cells are present in a given biopsy sample [19], while nested PCR is capable of detecting the bacterium as low as 3 cells only [14]. In the present study, we targeted 3 genes ( $h s p 60$, ureC, and fliI) to rule out possibility of PCR contamination and all the targets gave specific amplification in each antral biopsies collected from 23 of the 25 patients. Further, we have taken full precaution to avoid cross-contamination through endoscopes by proper sterilization and performing PCR in 3 completely separated rooms. These observations suggest that extremely sensitive methods of $H$. pylori should be employed specifically for evaluation of therapeutic efficacy.

Further, we tried to see whether the $H$. pylori strains detected pre- and posttherapy are similar or they are the cases of reinfection by new strains. All amplicon originating from 3 different targets from each of 23 patients subjected to restriction analysis showed that pre- and poststrains were identical. However, one amplicon of ureC origin and 6 of fliI were found to give different banding pattern than the initial amplification experiment on antral biopsy in the same patient. Although possibility of rising mutations during therapy cannot be ruled out, majority of patients were found to harbor the same strain after 4 weeks posttherapy which suggests that complete $H$. pylori eradication has not occurred in these patients. Our observation goes in the same line as reported previously, where the authors have shown that infection of $H$. pylori persists after therapy [20-26]. However, reinfection by the bacterium having identical restriction pattern may occur a result of recolonisation of stomach originating from the oral cavity of the same patients or contacting infection from a family member harboring the same strain [27]. It may also be quite likely, however, that $H$. pylori may survive in the gastric pits where sufficient concentration of antibiotics may not be achieved or bacteria transformed to coccoid (VBNC) that makes antibiotic ineffective. In an animal model, Cellini et al. (1994) demonstrated that up to 3 months after inoculation viable but not culturable forms of $H$. pylori could still be detected in the mouse stomach [28]. A few studies $[29,30]$ were carried out to evaluate triple therapy comparing PCR with culture. However no report has included nested PCR. Interestingly, Hammar et al. (1992) described gastric biopsy samples that were $H$. pylori positive by PCR but negative by culture [19]. Similar findings of persistence of $H$. pylori antigens, detected both with single round PCR and enzyme immunoassay (EIA), in the stool of successfully eradicated patients have been reported [31].

Therefore, it may be proposed that $H$. pylori causes chronic infection and usually eradication does not occur by anti-H. pylori regimens. The symptomatic relief occurring in the patients might be due to overall reduction in the bacterial density which might have aggravated the problem. Further, the possibility of presence of other bacteria than $H$. pylori causing acid peptic disease which are taken care off by the same antimicrobial agents may be also considered.

In conclusion, conventional methods to detect $H$. pylori especially posttherapy could not detect the pathogens as can be done by nested PCR protocol. Therefore, nested PCR may be proposed as the gold standard. Moreover, RUT, UBT, and histopathology are unable to discriminate the reinfection or recrudescence, while PCR based method (restriction analysis 
J99

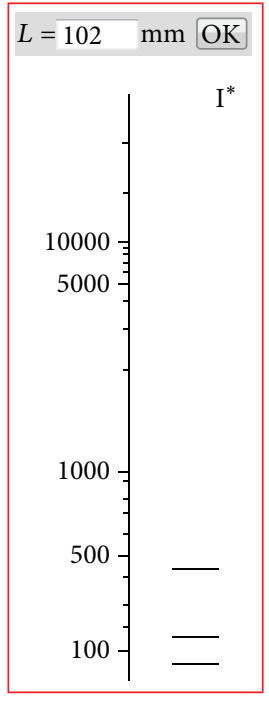

J99
KC525439

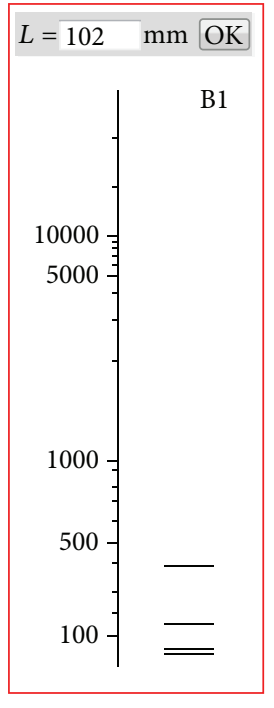

KC525439
KC525440

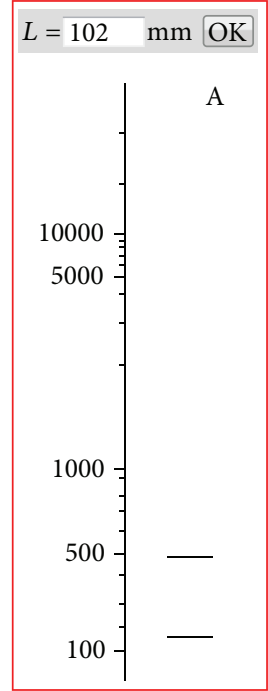

KC525440
KC525441

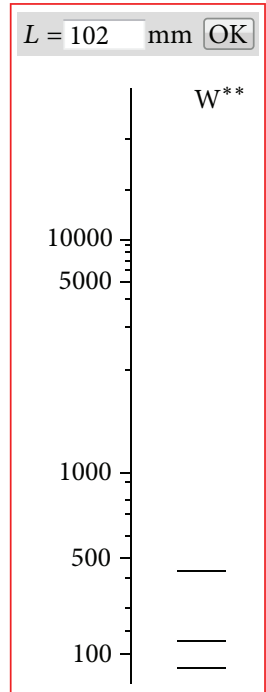

KC525441
KC525442

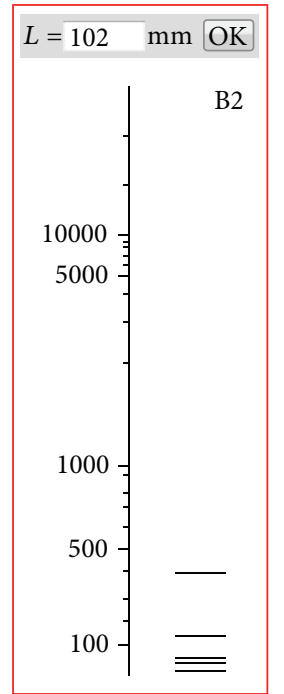

KC525442
KC525443

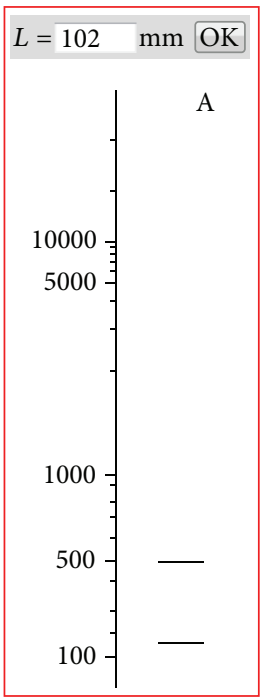

KC525443

$\begin{array}{lclc}\text { Coordinates } & \text { bp } & \text { Coordinates } & \text { bp } \\ 210-640 & 431 & 255-640 & 386 \\ 1-154 & 154 & 1-154 & 154 \\ 155-209 & 55 & 155-209 & 55 \\ & & 210-254 & 45\end{array}$

$\begin{array}{lclclc}\text { Coordinates } & \text { bp } & \text { Coordinates } & \text { bp } & \text { Coordinates } & \text { bp } \\ 210-640 & 431 & 255-640 & 386 & 155-640 & 86 \\ 1-154 & 154 & 23-154 & 132 & 1-154 & 154 \\ 155-209 & 55 & 155-209 & 55 & & \\ & & 210-254 & 45 & & \\ & & 1-22 & 22 & & \end{array}$

FIGURE 7: In silico restriction pattern of fli gene ( $640 \mathrm{bp}$ ) specific to $H$. pylori digested with $\mathrm{Mnl}$ I. The virtual gel was generated by interpolating experimental data using NEB cutter V2.0. KC525441 (GenBank accession number) represents in silico restriction pattern like J99; KC525439, KC525440, KC525442, and KC525443 produced varying restriction pattern. I* : restriction pattern of J99; $\mathrm{W}^{* *}$ : wild type restriction pattern; $\mathrm{A}, \mathrm{B} 1$, and B2: mutated/changed restriction pattern of $\mathrm{Mnl} \mathrm{I}$.

or sequencing) has capability to indicate either of the two possibilities.

\section{Conflict of Interests}

The authors have no conflict of interests.

\section{Acknowledgments}

This study was funded by the Department of Biotechnology, Government of India, Grant no. and sanction order no. 102/IFD/SAN/PR1310/2006-07. The authors gratefully acknowledged the Council of Scientific and Industrial Research (CSIR) New Delhi, India, in the form of Senior Research Fellowship awarded to Saurabh Kumar Patel.

\section{References}

[1] R. W. M. van der Hulst, J. J. Keller, E. A. J. Rauws, and G. N. J. Tytgat, "Treatment of Helicobacter pylori infection: a review of the world literature," Helicobacter, vol. 1, no. 1, pp. 6-19, 1996.

[2] International Agency for Research on Cancer, Schistosomes, Liver Flukes and Helicobacter pylori, vol. 61 of IARC Monographs on the Evaluation of Carcinogenic Risks to Humans, International Agency for Research on Cancer, Lyon, France, 1994.
[3] K. Kimura, K. Ido, K. Saifuku et al., "A 1-h topical therapy for the treatment of Helicobacter pylori infection," American Journal of Gastroenterology, vol. 90, no. 1, pp. 60-63, 1995.

[4] J. J. Y. Sung, S. C. S. Chung, T. K. W. Ling et al., "Antibacterial treatment of gastric ulcers associated with Helicobacter pylori," The New England Journal of Medicine, vol. 332, pp. 139-142, 1995.

[5] E. Bayerdorffer, G. A. Mannes, A. Sommer et al., "Longterm follow-up after eradication of Helicobacter pylori with a combination of omeprazole and amoxycillin," Scandinavian Journal of Gastroenterology, vol. 28, supplement 196, pp. 19-25, 1993.

[6] D. Y. Graham, A. R. Opekun, and P. D. Klein, "Clarithromycin for the eradication of Helicobacter pylori," Journal of Clinical Gastroenterology, vol. 16, no. 4, pp. 292-294, 1993.

[7] R. P. H. Logan, P. A. Gummett, H. D. Schaufelberger et al., "Eradication of Helicobacter pylori with clarithromycin and omeprazole," Gut, vol. 35, no. 3, pp. 323-326, 1994.

[8] H. Xia, M. A. Daw, S. Sant, S. Beattie, C. T. Keane, and C. A. O'Morain, "Clinical efficacy of triple therapy in Helicobacter pylori-associated duodenal ulcer," European Journal of Gastroenterology \& Hepatology, vol. 5, no. 3, pp. 141-144, 1993.

[9] T. U. Wheeldon, T. T. Hoang, D. C. Phung, A. Björkman, M. Granström, and M. Sörberg, "Long-term follow-up of Helicobacter pylori eradication therapy in Vietnam: reinfection and clinical outcome," Alimentary Pharmacology \& Therapeutics, vol. 21, no. 8, pp. 1047-1053, 2005. 
[10] T. Okimoto, K. Murakami, R. Sato et al., "Is the recurrence of Helicobacter pylori infection after eradication therapy resultant from recrudescence or reinfection, in Japan," Helicobacter, vol. 8, no. 3, pp. 186-191, 2003.

[11] J. P. Gisbert, I. G. Arata, D. Boixeda et al., "Role of partner's infection in reinfection after Helicobacter pylori eradication," European Journal of Gastroenterology and Hepatology, vol. 14, no. 8, pp. 865-871, 2002.

[12] P. Hildebrand, P. Bardhan, L. Rossi et al., "Recrudescence and reinfection with Helicobacter pylori after eradication therapy in Bangladeshi adults," Gastroenterology, vol. 121, no. 4, pp. 792798, 2001.

[13] H. X. Xia, H. J. Windle, D. G. Marshall, C. J. Smyth, C. T. Keane, and C. A. O'Morain, "Recrudescence of Helicobacter pylori after apparently successful eradication: novel application of randomly amplified polymorphic DNA fingerprinting," Gut, vol. 37, no. 1, pp. 30-34, 1995.

[14] V. Singh, S. Mishra, G. R. K. Rao et al., "Evaluation of nested PCR in detection of Helicobacter pylori targeting a highly conserved gene: HSP60," Helicobacter, vol. 13, no. 1, pp. 30-34, 2008.

[15] S. K. Patel, C. B. Pratap, A. K. Verma, A. K. Jain, V. K. Dixit, and G. Nath, "Pseudomonas fluorescens-like bacteria from the stomach: a microbiological and molecular study," World Journal of Gastroenterology, vol. 19, no. 7, pp. 1056-1067, 2013.

[16] S.-A. Ho, J. A. Hoyle, F. A. Lewis et al., "Direct polymerase chain reaction test for detection of Helicobacter pylori in humans and animals," Journal of Clinical Microbiology, vol. 29, no. 11, pp. 2543-2549, 1991.

[17] B. E. Dunn, H. Cohen, and M. J. Blaser, "Helicobacter pylori," Clinical Microbiology Reviews, vol. 10, no. 4, pp. 720-741, 1997.

[18] S. P. Cole, D. Cirillo, M. F. Kagnoff, D. G. Guiney, and L. Eckmann, "Coccoid and spiral Helicobacter pylori differ in their abilities to adhere to gastric epithelial cells and induce interleukin-8 secretion," Infection and Immunity, vol. 65, no. 2 , pp. 843-846, 1997.

[19] M. Hammar, T. Tyszkiewicz, T. Wadström, and P. W. O’Toole, "Rapid detection of Helicobacter pylori in gastric biopsy material by polymerase chain reaction," Journal of Clinical Microbiology, vol. 30 , no. 1, pp. 54-58, 1992.

[20] N. S. Taylor, J. G. Fox, N. S. Akopyants et al., "Long-term colonization with single and multiple strains of Helicobacter pylori assessed by DNA fingerprinting," Journal of Clinical Microbiology, vol. 33, no. 4, pp. 918-923, 1995.

[21] S. M. Salama, Q. Jiang, N. Chang, R. W. Sherbaniuk, and D. E. Taylor, "Characterization of chromosomal DNA profiles from Helicobacter pylori strains isolated from sequential gastric biopsy specimens," Journal of Clinical Microbiology, vol. 33, no. 9, pp. 1496-1497, 1995.

[22] W. Tee, J. Lambert, R. Smallwood, M. Schembri, B. C. Ross, and B. Dwyer, "Ribotyping of Helicobacter pylori from clinical specimens," Journal of Clinical Microbiology, vol. 30, no. 6, pp. 1562-1567, 1992.

[23] M. Costas, R. J. Owen, J. Bickley, and D. R. Morgan, "Molecular techniques for studying the epidemiology of infection by Helicobacter pylori," Scandinavian Journal of Gastroenterology, vol. 26, no. 181, pp. 20-32, 1991.

[24] R. J. Owen, J. Bickley, M. Costas, and D. R. Morgan, “Genomic variation in Helicobacter pylori: application to identification of strains," Scandinavian Journal of Gastroenterology, vol. 26, no. 181, pp. 43-50, 1991.
[25] J. H. Oudbier, W. Langenberg, E. A. J. Rauws, and C. BruinMosch, "Genotypical variation of Campylobacter pylori from gastric mucosa," Journal of Clinical Microbiology, vol. 28, no. 3, pp. 559-565, 1990.

[26] W. Langenberg, E. A. J. Rauws, H. J. Houthoff et al., "Followup study of individuals with untreated Campylobacter pyloriassociated gastritis and of noninfected persons with non-ulcer dyspepsia," The Journal of Infectious Diseases, vol. 157, no. 6, pp. 1245-1249, 1988.

[27] K. Schutze, E. Hentschel, B. Dragosics, and A. M. Hirschl, "Helicobacter pylori reinfection with identical organisms: transmission by the patients' spouses," Gut, vol. 36, no. 6, pp. 831-833, 1995.

[28] L. Cellini, N. Allocati, D. Angelucci et al., "Coccoid Helicobacter pylori not culturable in vitro reverts in mice," Microbiology and Immunology, vol. 38, no. 11, pp. 843-850, 1994.

[29] S. E. Perkins, L. L. Yan, Z. Shen, A. Hayward, J. C. Murphy, and J. G. Fox, "Use of PCR and culture to detect Helicobacter pylori in naturally infected cats following triple antimicrobial therapy," Antimicrobial Agents and Chemotherapy, vol. 40, no. 6, pp. 1486-1490, 1996.

[30] A. Rollan, R. Giancaspero, F. Fuster et al., "The long-term reinfection rate and the course of duodenal ulcer disease after eradication of Helicobacter pylori in a developing country," American Journal of Gastroenterology, vol. 95, no. 1, pp. 50-56, 2000.

[31] A. Makristathis, W. Barousch, E. Pasching et al., "Two enzyme immunoassays and PCR for detection of Helicobacter pylori in stool specimens from pediatric patients before and after eradication therapy," Journal of Clinical Microbiology, vol. 38, no. 10, pp. 3710-3714, 2000. 


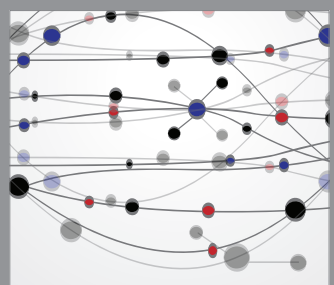

The Scientific World Journal
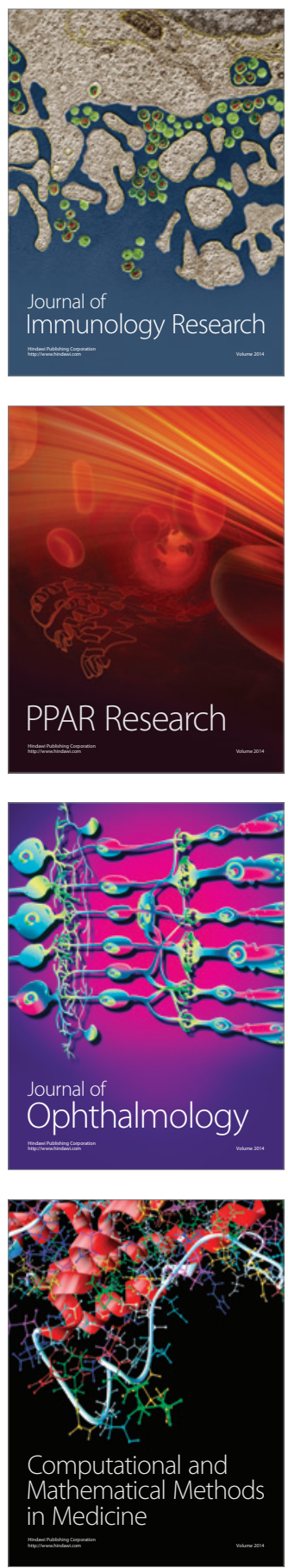

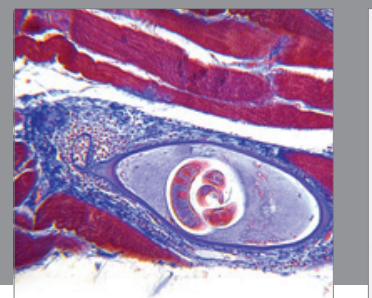

Gastroenterology

Research and Practice
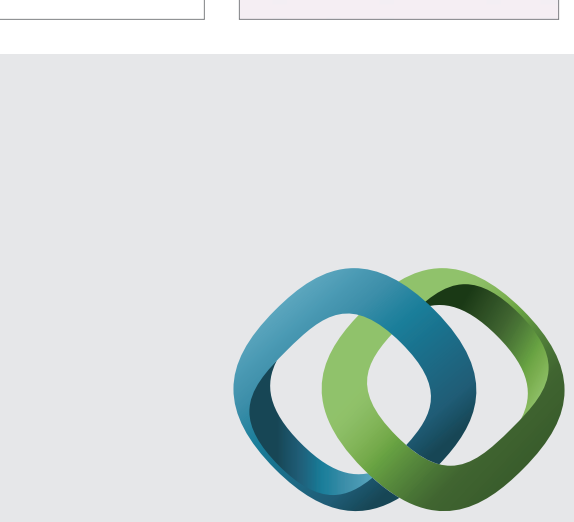

\section{Hindawi}

Submit your manuscripts at

http://www.hindawi.com
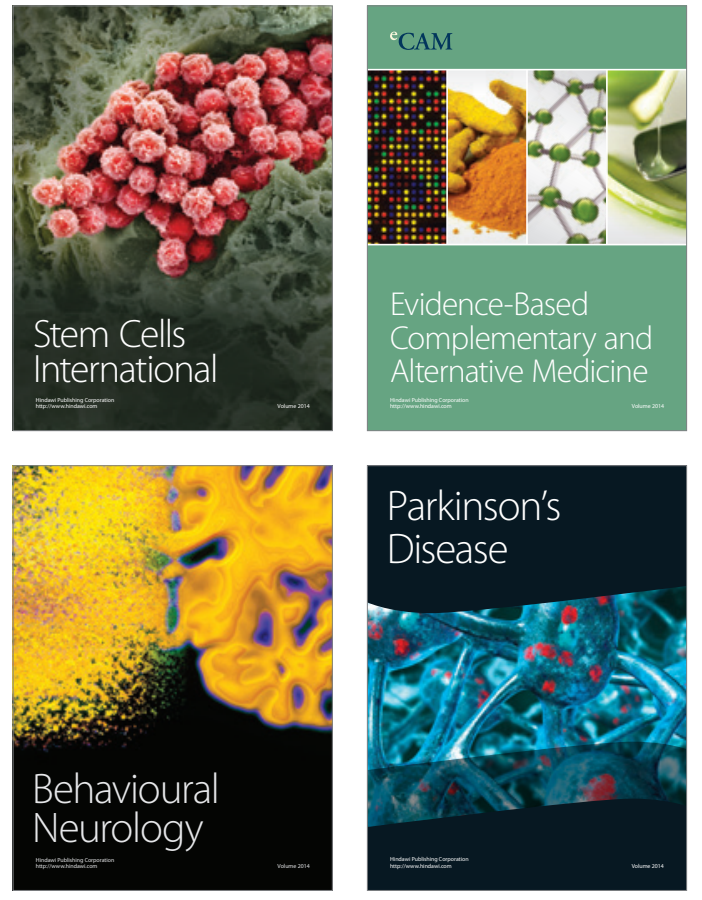
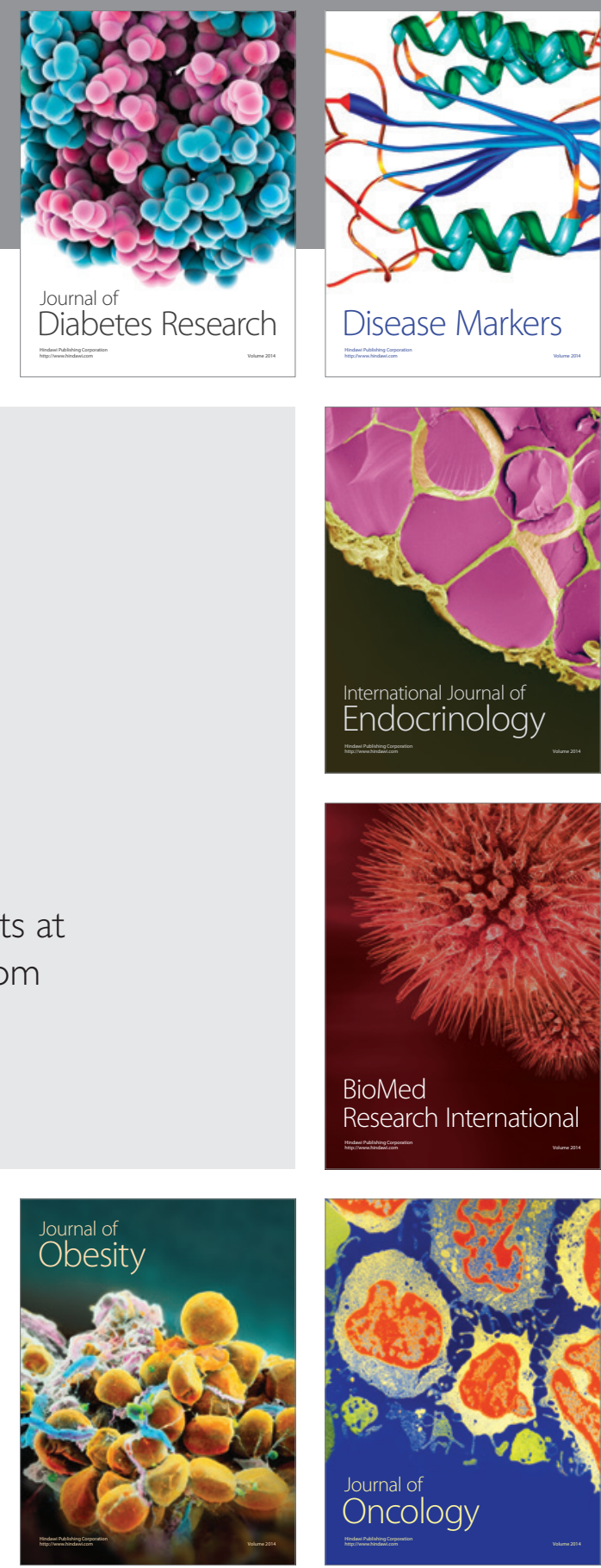

Disease Markers
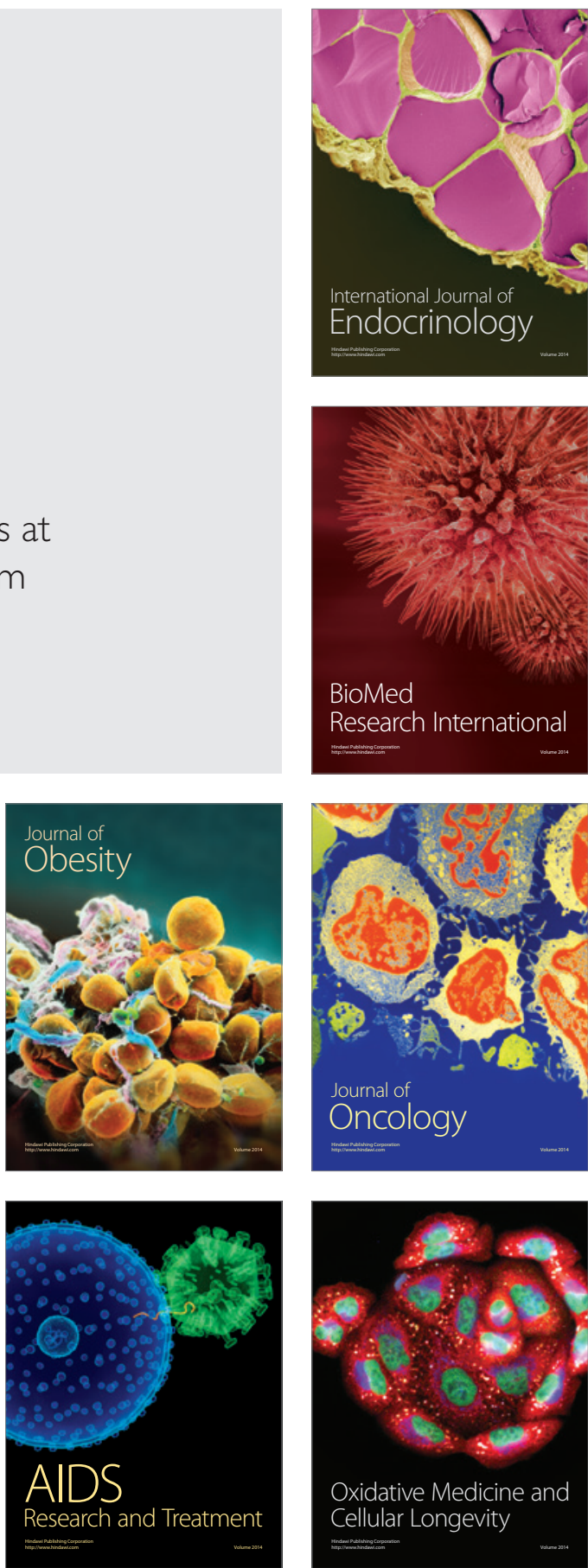